- ORIGINAL ARTICLE Volume 9 Issue 12017

DOI: 10.21315/eimj2017.9.1.2

ARTICLE INFO

Submitted: $18-09-2016$

Accepted: 26-12-2016

Online: 31-03-2017

\section{Assessment of First-Year Students' Metacognitive Ability in Faculty of Medicine, Universiti Sultan Zainal Abidin (UniSZA): Toward Curriculum Development}

\author{
Uday Younis Hussein Abdullah', Haitham Muhammed Jassim², Nor \\ Iza Abdul Rahman' ${ }^{1}$, Tg Fatimah Murniwati Tengku Muda' ${ }^{1}$ Nordin \\ Simbak , Shahid Hassan ${ }^{1}$ \\ ${ }^{1}$ Faculty of Medicine, Universiti Sultan Zainal Abidin (UniSZA), \\ Health Campus, Falan Sultan Mahmud, 20400 Kuala Terengganu, \\ Terengganu, Malaysia \\ ${ }^{2}$ Emergency Department, Rockingham Peel Group, South \\ Metropolitan Health Service, 33 Elanora Drive, Rockingham 6967, \\ PO Box 2033, West Australia, Australia
}

To cite this article: Abdullah UYH, Jassim HM, Abdul Rahman NI, Muda FM, Simbak N, Hassan S. Assessment of first-year students' metacognitive ability in Faculty of Medicine, Universiti Sultan Zainal Abidin (UniSZA): Toward curriculum development. Education in Medicine Journal. 2017; 9(1):17-28. https://doi.org/10.21315/eimj2017.9.1.2

To link to this article: https://doi.org/10.21315/eimj2017.9.1.2

\begin{abstract}
Introduction: Metacognition is the awareness of knowledge how one learns in addition to what one learns and to understand how a task will be performed. Metacognitive skill as self-assessment is recognised as an important contributor to the development of critical capacity, reflective attitude and autonomous life-long learning. Accurate, self-assessment of knowledge and skills is essential for students to maintain and improve through self-directed learning. Objective: The objective of this study was to explore, how well students' evaluate their own level of understanding for lectures to reflect their metacognitive skill that can be used in educational strategy to promote students' personal and professional growth. Methods: To assess the metacognition of the students, a questionnaire based on three items was designed. All 60 (17 male and 43 female) preclinical, first-year medical students were included in this study. The metacognition as planning, monitoring and evaluating the lecture was judged through students' response on 33 lectures in terms of understanding of knowledge, clearing of misconceptions and presenting of a well prepared material respectively in the field of haematology and parasitology. Metacognition as reflected in the lecture understanding level (LUL) score, lectures preparation level (LPL) score and students question level (SQL) score was estimated for its correlation with student' achievement score in pre-clinical phase of MBBS program. Results: The data was analysed for correlation between metacognition and overall students' achievement scores and a statistically significant correlation between LUL and multiple true false (MTF) of $268(p=.039)$, LPL and MTF of .282 ( $p=.029)$ as well as between SQL and MTF of .360 $(p=.005)$ was compared to poor correlation between LUL, LPL and SQL and the other three assessment tools (short essay questions $[\mathrm{SEQ}]$, problem-based questions $[\mathrm{PBQ}]$ and objectively structured practical examination [OSPE]) was found. Conclusion: The significant correlation of students' metacognition and their achievement score in classroom setting with MTF and poor correlation with SEQ, PBQ and OSPE is attributed to multiple factors discussed in this study, imperative to students' personal and professional growth.
\end{abstract}

Keywords: Metacognition, Cognition, Undergraduate medical students, Curriculum development

CORRESPONDING AUTHOR Prof. Dr. Shahid Hassan, International Medical University (IMU) Centre of Education, International Medical University, 126 Jalan Perkasa, Bukit Jalil, 57000 Kuala Lumpur, Malaysia | Email: shahidhassan@imu.edu.my 


\section{INTRODUCTION}

Some researchers claim mounting evidence that supplementing or replacing lectures with active learning strategies and engaging students in discovery and scientific process improves learning and knowledge retention (1). This concept leads to an innovative approach of metacognition in learning that adds a new dimension to competency-based learning model. A number of definitions and structures for metacognition have been proposed since the mid-1970 but it is still debated for it's in depth information, definition, conceptual model, implementation strategies and outcome objectives to define the innovative concepts of metacognition in learning. Metacognition has been referred by John Flavell, followed by a number of other researchers, as one's knowledge concerning cognitive processes and one's actively monitoring and regulating that cognitive process (1-4). The easily understood definition of metacognition has come from Schraw and Dennison and "It refers to the ability to reflect upon, understand and control one's learning" or in so many words, "thinking about one's thinking" (5). However, majority of researchers and literature are in congruence with the theoretical construct of metacognition into two major components; knowledge of cognition and regulation of cognition. Knowledge of cognition "describes an individual's awareness of cognition at three different levels: declarative knowledge (DK) or knowing about things, procedural knowledge (PK) or knowing about how to do things and conditional knowledge (CK) or knowing why and when to do things" (6-8). DK refers to the knowledge that learners have about the information or resources needed for undertaking the given tasks. DK is recently considered beyond the knowledge about oneself as learner to a state that include individuals' knowledge and understanding of self-efficacy and motivation indicating their affective phase of how they value factors that affect one's learning. With their DK an adult knows the capacity of their long term memory to plan accordingly to optimise learning (13). PK is about learner's ability to carry out a task to achieve a goal and it helps learners to set their learning strategies and it may reflect in conceptual map and summarising the main idea and periodic self-testing and it is about an individual's self-perceptions of how to do something (8). CK refers to knowledge relating to a situation in which students may use specific knowledge, skills, algorithms, techniques and method to perform a task. A person with conditional knowledge knows when, where and why to use a particular knowledge to complete a task in a different situation. CK is needed to assess the demand of learning situation and to apply the acquired knowledge learnt in a different situation to complete the task (14). Regulation of cognition, on the other hand, relates to how learners understand about their own learning abilities, which can be regulated by planning, monitoring and evaluating the learning skills. Metacognitive activities start before the cognitive activities (planning), during the activities (monitoring) or after the activities (evaluating) (Figure 1). Metacognition and cognition are two different but related terms. Metacognition is the awareness of knowledge how one learns in addition to what one learns. Metacognition is necessary to understand how a task will be performed, while cognition is required to fulfil a task (9). 


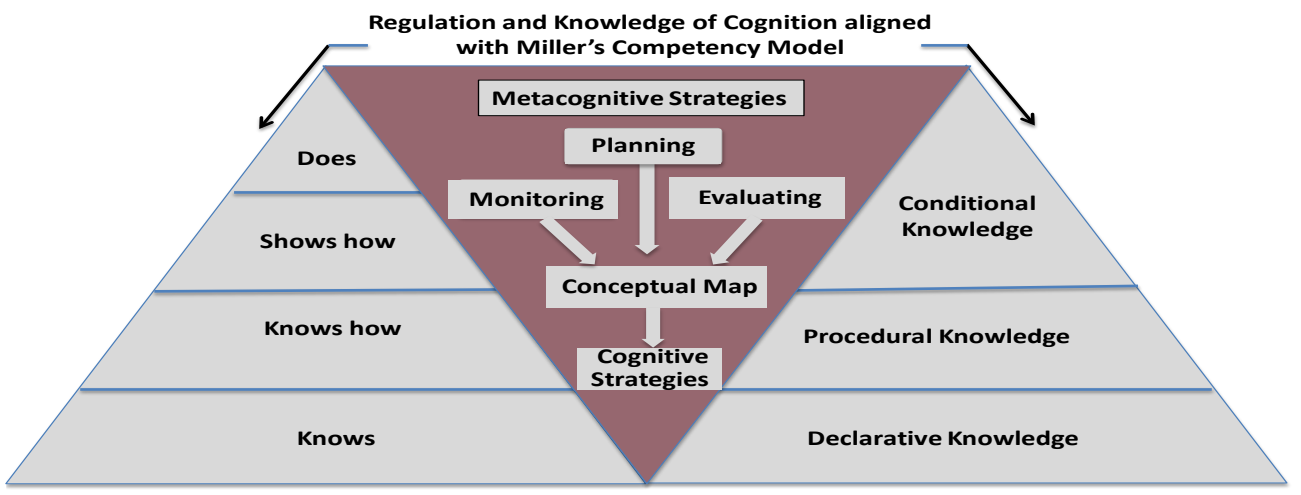

Miller's Competency Model with New Dimension of Metacognition

Figure 1: Metacognitive skills as an extension of Miller's pyramid of competency model and the relationship between metacognition and cognition.

Two primary problems are usually discussed with the term metacognition. In the first place, it is difficult to distinguish between terms meta and cognitive. Secondly, in the psychological research, metacognition has been used to refer to knowledge of cognition and regulation of cognition. In self-regulated learning theory, metacognition is recognised as skills that enable learners to understand and monitor their cognitive processes (12).

To measure student performance, traditional assessments involve the assessor (usually faculty) providing formative or summative feedback to the person being assessed (usually student) is routinely used. Assessment of student performance is a systematic procedure for measuring the progress or level of achievement of the students against defined criteria (15-18). The educational literature suggests that clinician self-awareness of their knowledge deficits, rather than the external influences, is more likely to bring about change in clinical practice (19). Honest self-assessment by medical students' and newly qualified doctor is recognised as an important contributor to the development of critical capacity, reflective attitude and autonomous life-long learning (20-23). There is broad acceptance of the importance of selfassessment in medical students' training; however research findings have been mixed. Early work suggested that students were good judges of their performance (24), but more recent studies have disputed this (25, 26).

The current state of affairs is looking for alternative approach for effective learning. It became important to review our teaching methods aiming to improve learning with regards to student's engagement in teaching and promotion of self-assessment and self-sufficient approach in learning. In current study, the objective was aimed to explore how well undergraduate students will feel confident of their own lectures understanding level and its correlation with achievement score. The metacognition was judged through students' response on LUL, LPL and SQL in the field of haematology and parasitology. LUL is explored as 'in-class-setting' reflection of students understanding. LPL explored as reflection of students' comments on material presented. SQL as reflection of students' asked questions on lecture contents. In addition, the study aimed to evaluate whether students' metacognition could be utilised as an educational strategy to the curriculum development and encourages personal and professional growth. The findings collected as students' response on three items survey were analysed for correlation among LUL, LPL and SQL and overall students' achievement scores in preclinical phase of MBBS program in Faculty 
of Medicine at the Universiti Sultan Zainal Abidin (UniSZA).

\section{METHOD}

Study design: It was a cross sectional study conducted in the pathology unit at faculty of medicine in Universiti Sultan Zainal Abidin (UniSZA), Kuala TerengganuMalaysia from December 2013 to May 2014 during the delivery of hematology and some parasitology lectures. A convenient sample of 64 first-year medical students of preclinical phase were included in the study however, four students were excluded due to their less than $80 \%$ attendance in lectures since a minimum of $80 \%$ attendance is the eligibility to sit the examination. Finally 60 students (20 male and 40 female) remained to accomplish the study. Participants were assured of confidentiality of information responded by them.

Assessment method: To assess the metacognition of the students included in this project, a questionnaire (Table 1) was designed. The questionnaire included: the lecture title and date, student's name and metric number, the student's response (in percent) for the level of understanding of lecture contents as well as student's response (in percent) for the level of lecture preparation and delivery. At the end, spaces for two essay questions from each student were provided and they were asked to put down their queries as two questions that may relate to their misconceptions about any area of the content or if they want to know any further information about the subject discussed in a specific lecture.

A total of 33 lectures (27 hematology lectures and 6 parasitology lectures) were included in this study. All the lectures were delivered by the first author (MD, Associate professor, university lecturer and researcher). Students were expected to come prepared for the lecture topics in each class. The questionnaire was distributed to every student at the beginning of the lecture and collected 5-10 minutes after the end of the lecture. The students were assured of confidentiality and allowed to rate and give their response in an absolutely free manner. Student response about their metacognition score was compared with their academic achievement score of end of the module assessment and respective semester exam. Student can respond to each of the two questions by selecting the appropriate box and writing down the percentage in terms of lecture content being understood (LUL) and students' comments on teaching material presented (LPL) after attending each lecture by the same lecturer.

Assessment tools: multiple true false (MTF), short essay questions (SEQ), objectively structured practical examination (OSPE) and problem-based questions (PBQ). Confidentiality of the data was strictly maintained and ethical approval was obtained [UniSZA/C/1/UHREC/628-1(55)] from the ethical committee in the Universiti Sultan Zainal Abidin (UniSZA).

Data analysis: Results were analysed using Statistical Package for Social Sciences (SPSS) version 18.0 for Windows. For each attribute, mean and standard deviation were calculated based on academic scores, metacognition as LUL score and LPL score and SQL score (Table 2). Level of significance was set at $p<0.05$. Pearson correlation was used to describe associations among mean achievement scores and LUL and LPL mean scores. All aspects of analysis mentioned in this research was compare with literature findings to see if the study is comparable or not and how this information can be used guide lecturers to review their teaching strategies to optimise the outcome of teaching in an outcome based education. Two questions invited by the students in questionnaire were categorised as explained in the legend of Table 1. This information will also be used to countercheck students' claim of understanding and clarification of misconceptions (metacognition). A correlation coefficient between metacognition as students' LUL score, LPL score and SQL score and students overall achievement score was established 
(Table 3). Coding of examination questions determined by the writer of each items versus panel of experts was compared to rule out its confounding effects on achievement score (Table 4). Ultimately the impact of coding of questions in terms of cognitive level (C1-C4) on achievement score of corresponding assessment tools established for test of cognitive domains was also be analysed as Pearson Correlation Coefficient ( $r$ ).

\section{RESULTS}

Table 1: Questionnaire-based survey on students' understanding the lecture, appreciating the preparation and asking the two relevant questions on lecture to be used for students perception of content delivered

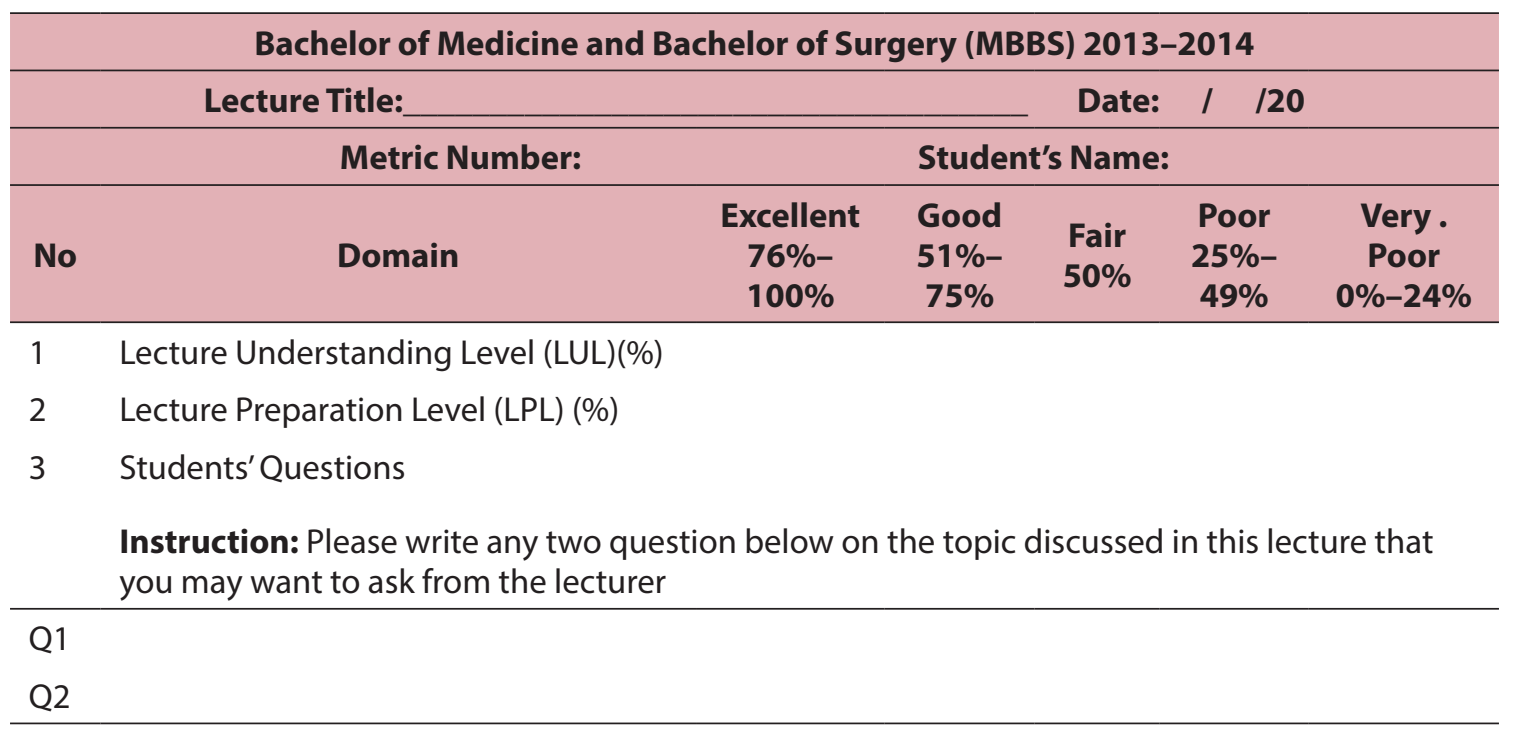

Note. 1: LUL is explored as 'in-class-setting' reflection of students understanding. 2: LPL explored as reflection of students' comments on material presented. 3: SQL as reflection of students' asked essay questions on lecture contents (Q1 and Q2) was categorised into: a) Above expectation if the question asked was related to matter a level beyond the subject discussed in lecture. b) Within expectation if the question asked was within the subject matter discussed in lecture.

c) Below expectation if the question asked was very basic that suggest even the minimal understanding of content was not met and the question was below the level the subject discussed.

Table 2: Students' response on two survey items and the achievement scores in different assessment tools

\begin{tabular}{|c|c|c|c|c|c|c|c|}
\hline \multirow{2}{*}{$\begin{array}{l}\text { Student } \\
\text { ID }\end{array}$} & \multirow{2}{*}{$\begin{array}{c}\text { Lecture } \\
\text { Understanding } \\
\text { Level (LUL) (\%) }\end{array}$} & \multirow{2}{*}{$\begin{array}{c}\text { Lecture } \\
\text { Preparation } \\
\text { Level (LPL) } \\
\text { (\%) }\end{array}$} & \multirow{2}{*}{$\begin{array}{c}\text { Student } \\
\text { Question } \\
\text { Level (SQL) } \\
\text { (\%) }\end{array}$} & \multicolumn{4}{|c|}{ Examination Score (\%) } \\
\hline & & & & MTF & SEQ & PBQ & OSPE \\
\hline 1 & 65 & 74 & 100 & 74 & 51 & 70 & 85 \\
\hline 2 & 85 & 95 & 100 & 71 & 66 & 70 & 68 \\
\hline 3 & 88 & 95 & 100 & 77 & 71 & 66 & 96 \\
\hline 4 & 78 & 80 & 97 & 74 & 75 & 74 & 88 \\
\hline 5 & 80 & 82 & 87 & 60 & 69 & 48 & 98 \\
\hline 6 & 78 & 83 & 77 & 80 & 78 & 66 & 81 \\
\hline
\end{tabular}


Table 2: (continued)

\begin{tabular}{|c|c|c|c|c|c|c|c|}
\hline \multirow{2}{*}{$\begin{array}{l}\text { Student } \\
\text { ID }\end{array}$} & \multirow{2}{*}{$\begin{array}{c}\text { Lecture } \\
\text { Understanding } \\
\text { Level (LUL) (\%) }\end{array}$} & \multirow{2}{*}{$\begin{array}{c}\text { Lecture } \\
\text { Preparation } \\
\text { Level (LPL) } \\
(\%)\end{array}$} & \multirow{2}{*}{$\begin{array}{c}\text { Student } \\
\text { Question } \\
\text { Level (SQL) } \\
\text { (\%) }\end{array}$} & \multicolumn{4}{|c|}{ Examination Score (\%) } \\
\hline & & & & MTF & SEQ & PBQ & OSPE \\
\hline 7 & 79 & 84 & 100 & 77 & 72 & 74 & 93 \\
\hline 8 & 81 & 84 & 97 & 71 & 67 & 80 & 95 \\
\hline 9 & 76 & 84 & 100 & 68 & 50 & 42 & 71 \\
\hline 10 & 77 & 84 & 100 & 77 & 62 & 64 & 91 \\
\hline 11 & 77 & 86 & 100 & 74 & 74 & 72 & 74 \\
\hline 12 & 78 & 87 & 93 & 71 & 58 & 72 & 90 \\
\hline 13 & 78 & 87 & 100 & 57 & 74 & 84 & 95 \\
\hline 14 & 79 & 87 & 100 & 77 & 62 & 76 & 83 \\
\hline 15 & 78 & 88 & 100 & 82 & 77 & 68 & 86 \\
\hline 16 & 79 & 88 & 100 & 77 & 72 & 70 & 81 \\
\hline 17 & 79 & 88 & 100 & 83 & 84 & 36 & 82 \\
\hline 18 & 79 & 87 & 97 & 65 & 53 & 76 & 93 \\
\hline 19 & 78 & 88 & 90 & 71 & 57 & 64 & 89 \\
\hline 20 & 78 & 88 & 83 & 65 & 52 & 82 & 85 \\
\hline 21 & 78 & 89 & 97 & 77 & 76 & 70 & 98 \\
\hline 22 & 79 & 88 & 80 & 64 & 72 & 78 & 80 \\
\hline 23 & 78 & 89 & 63 & 57 & 64 & 86 & 90 \\
\hline 24 & 79 & 89 & 90 & 65 & 62 & 66 & 63 \\
\hline 25 & 80 & 89 & 87 & 65 & 60 & 70 & 85 \\
\hline 26 & 79 & 89 & 97 & 77 & 70 & 70 & 93 \\
\hline 27 & 80 & 89 & 93 & 68 & 75 & 80 & 85 \\
\hline 28 & 79 & 89 & 87 & 65 & 67 & 86 & 91 \\
\hline 29 & 79 & 89 & 97 & 68 & 67 & 66 & 72 \\
\hline 30 & 80 & 90 & 73 & 60 & 62 & 80 & 81 \\
\hline 31 & 79 & 90 & 90 & 74 & 46 & 72 & 93 \\
\hline 32 & 80 & 90 & 87 & 65 & 50 & 66 & 81 \\
\hline 33 & 98 & 90 & 93 & 60 & 54 & 48 & 77 \\
\hline 34 & 79 & 89 & 97 & 65 & 62 & 76 & 94 \\
\hline 35 & 79 & 89 & 93 & 60 & 64 & 60 & 74 \\
\hline 36 & 78 & 89 & 83 & 65 & 57 & 64 & 90 \\
\hline 37 & 78 & 90 & 77 & 62 & 72 & 60 & 89 \\
\hline 38 & 78 & 90 & 97 & 60 & 59 & 70 & 68 \\
\hline 39 & 78 & 90 & 70 & 71 & 55 & 76 & 67 \\
\hline 40 & 78 & 90 & 83 & 77 & 71 & 74 & 96 \\
\hline 41 & 78 & 90 & 77 & 60 & 72 & 50 & 81 \\
\hline
\end{tabular}


Table 2: (continued)

\begin{tabular}{|c|c|c|c|c|c|c|c|}
\hline \multirow{2}{*}{$\begin{array}{l}\text { Student } \\
\text { ID }\end{array}$} & \multirow{2}{*}{$\begin{array}{c}\text { Lecture } \\
\text { Understanding } \\
\text { Level (LUL) (\%) }\end{array}$} & \multirow{2}{*}{$\begin{array}{c}\text { Lecture } \\
\text { Preparation } \\
\text { Level (LPL) } \\
\text { (\%) }\end{array}$} & \multirow{2}{*}{$\begin{array}{c}\text { Student } \\
\text { Question } \\
\text { Level (SQL) } \\
\text { (\%) }\end{array}$} & \multicolumn{4}{|c|}{ Examination Score (\%) } \\
\hline & & & & MTF & SEQ & PBQ & OSPE \\
\hline 42 & 78 & 90 & 87 & 71 & 67 & 64 & 85 \\
\hline 43 & 78 & 90 & 97 & 82 & 63 & 54 & 81 \\
\hline 44 & 78 & 91 & 90 & 82 & 73 & 62 & 76 \\
\hline 45 & 78 & 90 & 97 & 71 & 82 & 62 & 90 \\
\hline 46 & 78 & 91 & 80 & 68 & 60 & 76 & 61 \\
\hline 47 & 78 & 91 & 93 & 65 & 54 & 66 & 60 \\
\hline 48 & 78 & 91 & 87 & 77 & 75 & 62 & 75 \\
\hline 49 & 78 & 91 & 90 & 65 & 52 & 16 & 95 \\
\hline 50 & 77 & 91 & 97 & 65 & 64 & 62 & 94 \\
\hline 51 & 78 & 91 & 90 & 71 & 44 & 68 & 92 \\
\hline 52 & 78 & 91 & 87 & 74 & 66 & 76 & 80 \\
\hline 53 & 78 & 91 & 83 & 74 & 62 & 48 & 88 \\
\hline 54 & 77 & 91 & 83 & 66 & 62 & 65 & 71 \\
\hline 55 & 78 & 91 & 97 & 63 & 70 & 70 & 83 \\
\hline 56 & 78 & 91 & 87 & 65 & 60 & 50 & 77 \\
\hline 57 & 78 & 91 & 93 & 65 & 65 & 56 & 73 \\
\hline 58 & 78 & 91 & 87 & 68 & 66 & 70 & 89 \\
\hline 59 & 78 & 92 & 93 & 71 & 57 & 78 & 84 \\
\hline 60 & 78 & 92 & 90 & 71 & 57 & 40 & 73 \\
\hline
\end{tabular}

Note: Student's response (in percent) for the LUL as well as student's response (in percent) for the LPL and SQL with the Examination Score (\%) of the different assessment tools used.

Table 3: The Pearson's correlations among the LUL, LPL and SQL with various assessment scores

\begin{tabular}{lccccc}
\hline & SQL & SEQ & PBQ & MTF & OSPE \\
\hline Lecture understanding level (LUL) & .042 & -.012 & -.061 & $.268^{*}$ & -.017 \\
Lecture preparation level (LPL) & $(.747)$ & $(.928)$ & $(.642)$ & $(.039)$ & $(.899)$ \\
& -.191 & -.090 & .083 & $.282^{*}$ & .215 \\
Student question level (SQL) & $(.143)$ & $(.493)$ & $(.530)$ & $(.029)$ & $(.100)$ \\
& 1 & .021 & -.102 & $.360^{*}$ & .113 \\
\end{tabular}

${ }^{*}$ Correlation is significant at the 0.05 -level (2-tailed). 
A moderate correlation established between LUL and MTF of $268(p=.039)$ was significant compared to poor correlation between LUL and three assessment tools respectively: SEQ $=-.012(p=.928), \mathrm{PBQ}$ $=-.061(p=.642)$ and OSPE $=-.017$ $(p=.899)$. Correlation was observed between lecture preparation level (LPL) estimated by students and the four assessment tools; MTF of .282 ( $p=.029)$, SEQ $=-.090(p=.493), \mathrm{PBQ}=.083$ $(p=.530)$ and OSPE $=.215(p=.100)$. Correlation between the SQL and the students' achievement score were found poor SEQ $=-.012(p=.875), \mathrm{PBQ}$ $=-.102(p=.436)$ and OSPE $=.113$ ( $p=.391)$ except in case of MTF that showed a significant correlation of .360 $(p=.005)$.

All the items were examined for their coding by a panel of expert comprising of subject specialist and medical educationist $(92 \%$ items in MTF were established as $\mathrm{C} 1$, while remaining $8 \%$ items were $\mathrm{C} 2$ and none of the items were $\mathrm{C} 3$ or $\mathrm{C} 4$ in $\mathrm{MTF}$ ).

Table 4: Weighting (coding) of cognitive and psychomotor domains of assessment tools.

\begin{tabular}{|c|c|c|c|c|}
\hline \multirow{2}{*}{ Assessment Tool } & \multicolumn{4}{|c|}{ Cognitive (Bloom's) Educational Taxonomy Coding of Assessment Items } \\
\hline & Recall (C1) & Understand (C2) & Apply (C3) & Analyse (C4) \\
\hline MTF & $46 / 50(92 \%)$ & $4 / 50(8 \%)$ & $0 / 50(0 \%)$ & $0 / 50(0 \%)$ \\
\hline SEQ & $1 / 10(10 \%)$ & $9 / 10(90 \%)$ & $0 / 50(0 \%)$ & $0 / 50(0 \%)$ \\
\hline \multirow[t]{3}{*}{ PBQ } & $1 / 8(12.5 \%)$ & $1 / 8(12.5 \%)$ & $6 / 8(75 \%)$ & $0 / 50(0 \%)$ \\
\hline & \multicolumn{4}{|c|}{ Psychomotor (Simpson's) Educational Taxonomy Coding of Assessment Items } \\
\hline & $\begin{array}{l}\text { Perception } \\
\text { (P1) }\end{array}$ & Set (P2) & $\begin{array}{c}\text { Guided } \\
\text { Response (P3) }\end{array}$ & Mechanism (P4) \\
\hline OSPE & $7 / 25(28 \%)$ & $3 / 25(12 \%)$ & $8 / 25(32 \%)$ & $7 / 25(28 \%)$ \\
\hline
\end{tabular}

Note: MTF = Multiple True False, SEQ = Short Essay Question, $\mathrm{PBQ}=$ Problem Based Question, OSPE = Objective Structural Physical Examination

\section{DISCUSSION}

Students' reflection to LUL of survey was expected to range from poor understanding (Table 2) to high understanding and an evidence to that was sought by analysing the Pearson's correlation between understanding LUL percentage (LUL \%) and achievement scores in the end of the module and at the end of semester examination (Table 3).Similarly, the reflection to LPL of survey was to reflect how clearly the topic was presented and how presentation skills help the students clarify misconception as the students' were asked to give their opinion on LPL (Table 2). This item of survey was considered students' reflection on evaluation component of metacognition in terms of appropriate material and personal attachment with text for enjoyment and credibility in comprehension. The two essay questions relevant to the topic discussed by the lecturer were analysed to reflect on in-classroom monitoring of students comprehension through the text and level of question inquired for basic, moderate or advance knowledge of subject discussed in a classroom setting. Finally a correlation coefficient was established between the three variables and the achievement scores (Table 3). A moderate correlation between LUL and MTF of $268(p=.039)$ was significant compared to poor correlation between LUL and three assessment tools respectively SEQ $=-.012(p=.928), \mathrm{PBQ}=-.061(p=.642)$ and OSPE $=-.017(p=.899)$. This finding shows overestimated of understanding by the students in case of SEQ, PBQ and OSPE indicating poor metacognitive skills demonstrated as declarative knowledge by the majority students when they were asked to commit on their understanding of knowledge discussed in those lectures. 
However, a significant correlation in MTF raised the question of quality of test items set to test the knowledge at recall or comprehension level of cognitive domain (cognitive level 1 or $\mathrm{C} 1$ and cognitive level 2 or C2 of Bloom's taxonomy). With MTF it is difficult to produce items that may test learning domains beyond C2 and items usually test the low order thinking that also favour the students learning style to become rote learners. Malaysian Qualifications Agency (MQA) and Ministry of Education (MOE) in Malaysia recommend evenly distributed minimum of $\mathrm{C} 1-\mathrm{C} 4$ test items in undergraduate medical education. This is to promote analytic reasoning and problem solving skills in learning in outcome-based education (OBE) approach that Malaysia is part of countries practicing this learning approach. The problem of rote-learning is that a student becomes superficiallearner, who believe in passing the exam with factual knowledge (knows) utilising short-term memory. Students with this learning style usually give less importance to procedural knowledge (knows how) and simply attending the lecture mean a lot to them and they often overestimate their selfefficacy and that is the reason they scored high in LUL \%. A test of high order thinking with SEQ, PBQ or OSPE items are easier to structure by academic staff but difficult to answer by students with superficial learning style. To countercheck this likely reason, all the items were examined for their coding of C1 (recall), C2 (comprehension), C3 (application) and C4 (analysis) by a panel of expert comprising of subject specialist (hematology and parasitology) and medical educationist. Remarkably $92 \%$ items in MTF were established as C1, while remaining $8 \%$ items were $\mathrm{C} 2$ (see table 4 ). None of the items were C3 or C4 in MTF. Another likely reason of poor performance in SEQ, PBQ and OSPE could have been the writing and communication skills, which was reported generally poor in majority of students in this cohort. The correlation shown between the SQL and the students' achievement score were found poor SEQ $=-.012(p=.875), \mathrm{PBQ}=-.102(p=$
$.436)$ and OSPE $=.113(p=.391)$ except in case of MTF that showed a significant correlation of $.360(p=.005)$. Same reason is attributed to good correlation of SQL with MTF and students monitoring of their learning process of in-class teaching evident from their question level were indicative of poor contextualisation to what content of a lecture was all about.

The ideal for a self-testing would be to take up quizzes, puzzles or scenarios relevant to the topics and solve those to test their problem solving and critical thinking in a self-monitoring learning. Author now regularly use post lecture quizzes of simple to more complex nature to let students know about their level of knowledge of cognition achieved after the lecture. However, in current study the same was evaluated indirectly keeping with in-class monitoring of lecture through level of questions asked by each student reflecting on their higher order thinking stimulated as a result of attending a lecture in the class. A more direct evaluation of students' achievement in current study was the test of conditional knowledge. A similar correlation was also observed between LPL estimated by students and the four assessment tools; MTF of .282 ( $p=.029)$, $\mathrm{SEQ}=-.090(p=.493), \mathrm{PBQ}=.083$ $(p=.530)$ and OSPE $=.215(p=.100)$. However, a very poor correlation between LPL and three assessment tools is also attributed to superficial learning style and poor writing and communication skills. In other studies, an association between level of achievement and accurate selfassessment has been documented, with high achieving students underestimating their competence and low achievers inflating their self-assessments (27, 28). Male students' tendency to overestimate and female student's tendency to underestimate their performance (29-31) was not considered in this study.

A review of the relevant literature and description of basic principle of metacognition using in-class assessment of teaching with formal lecture has been 
presented. Formal lecture widely used as a method of teaching has been losing its popularity among the students however, is still considered one of the most practiced methods of teaching in preclinical and clinical phase of undergraduate teaching in medical education. More innovative approaches and models such as problem based learning (PBL), case based learning (CBL) and team based learning (TBL) still require to use traditional ectures in their introductory or debriefing phase of these teaching methods. Lecturers from basic sciences disciplines still find formal lectures as the most important methods to cover entire content in a given curriculum. This might be the reason that these minimally guided model (PBL, CBL or TBL) though being practiced for over a half century has not been decisively claimed to achieve the outcome objectives of these methods in learning. The past half-century of empirical research on this issue has provided overwhelming and unambiguous evidence that minimal guidance during instruction is significantly more efficient than guided learning however, some researchers believe that minimally guided instruction is likely to be ineffective (32). For a classroom practice of measuring students' metacognitive ability to create awareness among students and teachers as how metacognitive skills are necessary to understand the learning process to accomplish the cognition required to fulfil the task in a routine learning.

\section{CONCLUSIONS}

This study was the first step of trying to understand students' metacognitive knowledge of preclinical phase of MBBS program. The results of this study indicated poor correlation between students' perceptions of comprehending the lecture for metacognitive strategies of planning, monitoring and evaluting as orientation of cognitive strategies in classroom setting. Moreover, this study develops in-class measure of students' metacognitive ability towards planning reflected as students' lecture understanding level, monitoring reflected as students' comprehension to ask quality question and evaluating showed as students appreciation of presentation material and attachment to text. We recommend further research to develop validated metacognitive inventory keeping in view the basic structure of metacognitive strategy, structuring of MTF with higher order of cognition beyond cognition level of $\mathrm{C} 1$, introducing new assessment tools of test of high level thinking such as one or single best questions (O/SBA) or extended matching question (EMQ), reviewing the teaching methods beyond formal lecture to introduce interactive lectures, team-based learning or restructuring and adding on PBL slots to current practice and introducing quizzes in lectures as a continuous assessment within modules.

\section{REFERENCES}

1. Schraw G, Crippen KJ, Hartley K. Promoting self-regulation in science education: metacognition as part of a broader perspective on learning. Res Sci Educ. 2006;36(1):111-39. https://doi. org/10.1007/s11165-005-3917-8

2. Handelsman J, Ebert-May D, Beichner R, Bruns P, Chang A, DeHaan R, et al. Scientific teaching. Science. 2004;304(5670):521-2. https://doi.org/10.1126/science.1096022

3. Cooper JL, MacGregor J, Smith KA, Robinson P. Implementing small-group instruction: insights from successful practitioners. New Directions in Teaching \& Learning. 2000;81:64-76. https://doi. org $/ 10.1002 / \mathrm{tl} .8105$

4. Cooper MM. Cooperative learning: An approach for large enrollment courses. J Chem Educ. 1995;72(2):162-4. https://doi. org/10.1021/ed072p162

5. Schraw G, Dennison RS. Assessing metacognitive awareness. Contemporary Educational Psychology. 1994;19(4):460-75. https://doi.org/10.1006/ceps.1994.1033 
6. Felder RM, Brent R. FAQs. II. (a) active learning vs. covering the syllabus; (b) dealing with large classes. Chem Engr Education. 1999;33(4):276-7.

7. Schraw G, Crippen KJ, Hartley K. Promoting self-regulation in science education: metacognition as part of a broader perspective on learning. Res Sci Edu. 2006;36:111-39. https://doi. org/10.1007/s1 1165-005-3917-8

8. Cooper MM, Sandi-Urena S. Design and validation of an instrument to assess metacognitive skillfulness in chemistry problem solving. J Chem Educ. 2009;86(2):240-5. https://doi.org/10.1021/ ed086p 240

9. Tabish SA. Assessment methods in medical education. Int. J. Health Sci. 2008;2:3-7.

10. Hartman HJ. Metacognition in teaching and learning: an introduction. Instruct Sci. 1998;26(1):1-3. https://doi.org/10 $.1023 / \mathrm{A}: 1003023628307$

11. Georghiades, P. From the general to the situated: three decades of metacognition. Intern J Sci Edu. 2004;26(3):365-83. https:// doi.org/10.1080/0950069032000119401

12. Mytkowicz P, Goss D, Steinberg B, College C. Assessing metacognition as a learning outcome in a postsecondary strategic learning course. J Postsecond Edu Disability. 2014;27:51-62.

13. Kirschner PA, Sweller J, Clark RE. Why minimal guidance during instruction does not work: an analysis of the failure of constructivist, discovery, problem-based, experiential, and inquiry based teaching. Educational Psychologist. 2006;41(2):75-86. https://doi.org/10.1207/s15326985ep4102_1

14. Schraw G, Moshman D. Metacognitive theories. Educ Psychol Rev. 1995;7(4):351173-371208. https://doi.org $/ 10.1007 / \mathrm{BF} 02212307$
15. Hendricson WD, Andrieu SC, Chadwick DG, Chmar JE, Cole JR, George MC, et al. Educational strategies associated with development of problem-solving, critical thinking, and self-directed learning. J Dent Educ. 2006;70:925-36.

16. Boud DFN. Quantitative studies of student self-assessment in higher education: a critical analysis of findings. Higher Educ. 1989;18(5):529-49. https://doi.org/10.1007/ BF00138746

17. Asadoorian J, Batty HP. An evidencebased model of effective self-assessment for directing professional learning. J Dent Educ. 2005;69:1315-23.

18. Sanson-Fisher RW, Rolfe IE, Jones P, Ringland C, Agrez M. Trialing a new way to learn clinical skills: systematic clinical appraisal and learning. Med Educ. 2002;36(11):1028-34. https://doi.org/10 $.1046 / \mathrm{j} .1365-2923.2002 .01334 . x$

19. Dijkstra J, V an der Vleuten CPM, Schuwirth LWT. A new framework for designing programmes of assessment. Adv Health Sci Educ Theory Pract. 2010; 15(3):379-93. https://doi.org/10.1007/ s10459-009-9205-z

20. Bloom BS. Taxonomy of educational objectives. Handbook I: cognitive domain. New York: David McKay; 1956.

21. Bandura, A. Self-efficacy: Toward a unifying theory of behavioral change. Psychological Review. 1977;84(2):191-215. https:/doi. org/10.1037/0033-295X.84.2.191

22. Cambra-Fierro, J,. Cambra-Berdun. J. Students' self-evaluation and reflection (part 2): an empirical study. Education + Training. 2007;49(2):103-11. https://doi. org/10.1108/00400910710739469

23. McDonald B, Boud D. The impact of self-assessment training on performance in external examinations. Assessment in Education: Principles, Policy \& Practice. 2003;10(2):209-20. https://doi.org/10.1080 /0969594032000121289 
24. Walsh, K. How to assess your learning needs. J R Soc Med. 2006;99:29-31.

25. Morton JB, Macbeth WG. Correlations between staff, peer and self-assessments of fourth-year students in surgery. Med Educ. 1977;11:167-70.

26. Eva KW, Cunningham JP, Reiter HI, Keane DR, Norman GR. How can I know what I don't know? Poor self-assessment in a welldefined domain. Adv Health Sci Educ Theory Prac. 2004;9(3):211-24. https://doi. org/10.1023/B:AHSE.0000038209.65714. d4

27. Srinivasan $M$, Hauer KE, Der-Maartirosian C, Wilkes M, Gesundhett N. Does feedback matter? Practice-based learning for medical students after a multi-institutional clinical performance examination. Med Educ 2007;41(9):857-65. https://doi.org/10.1111 /j.1365-2923.2007.02818.x

28. Rudy D, Fejfar M, Griffith C, Wilson J. Self- and peer assessment in first-year communication and interviewing course. Eval Health Prof. 2001;24(4):436-45. https://doi.org/10.1177 /016327870102400405
29. Mandel L, Goff B, Lentz G. Self-assessment of resident surgical skills: Is it feasible? Am J Obstet and Gynaecol. 2005;193(5):1817-22. https://doi.org/10.1016/j.ajog.2005.07.080

30. Evans AW, Leeson RMA, Newton-John TRO. The influence of self-deception and impression management on surgeons' self-assessment scores. Med Educ. 2002; 376(11):1095. https://doi.org/10.1046/j.1365 $-2923.2002 .134612 . x$

31. Rees CE. Self-assessment scores and gender. Med Educ. 2003;37(6):572-73. https://doi. org/10.1046/j.1365-2923.2003.01545.x

32. Kirschner PA, Sweller J, Clark RE. Why minimal guidance during instruction does not work: An analysis of the failure of constructivist, discovery, problem-based, experiential, and inquiry-based teaching. Educational Psychologist. 2006;41:75-86. https://doi.org/10.1207/s15326985ep4102_1 